\title{
A Randomized, Controlled Trial of Sequential Bilateral Repetitive Transcranial Magnetic Stimulation for Treatment-Resistant Depression
}

Paul B. Fitzgerald, M.B.B.S., M.P.M., Ph.D., F.R.A.N.Z.C.P.

Jessica Benitez, B.Sci., Grad. Cert. Clin. Nurse (Psych.)

Anthony de Castella, B.A., Dip. App. Sci.

Z. Jeff Daskalakis, M.D., F.R.C.P.(C.)

Timothy L. Brown, Grad. Dip. Clin. Nurse (Psych.)

Jayashri Kulkarni, M.B.B.S., M.P.M., Ph.D., F.R.A.N.Z.C.P.
Objective: High-frequency left-side repetitive transcranial magnetic stimulation (rTMS) and low-frequency stimulation to the right prefrontal cortex have both been shown to have antidepressant effects, but doubts remain about the magnitude of previously demonstrated treatment effects. The authors evaluated sequentially combined high-frequency left-side rTMS and low-frequency rTMS to the right prefrontal cortex for treatment-resistant depression.

Method: The authors conducted a 6week double-blind, randomized, shamcontrolled trial in 50 patients with treatment-resistant depression. Three trains of low-frequency rTMS to the right prefrontal cortex of 140 seconds' duration at $1 \mathrm{~Hz}$ were applied daily, followed immediately by 15 trains of 5 seconds' duration of highfrequency left-side rTMS at $10 \mathrm{~Hz}$. Sham stimulation was applied with the coil angled at $45^{\circ}$ from the scalp, resting on the side of one wing of the coil. The primary outcome variable was the score on the Montgomery-Åsberg Depression Rating Scale.

Results: There was a significantly greater response to active than sham stimulation at 2 weeks and across the full duration of the study. A significant proportion of the study group receiving active treatment met response (11 of 25 [44\%]) or remission (nine of 25 [36\%]) criteria by study end compared to the sham stimulation group (two of 25 [8\%] and none of 25 respectively).

Conclusions: Sequentially applying both high-frequency left-side rTMS and low-frequency rTMS to the right prefrontal cortex, has substantial treatment efficacy in patients with treatment-resistant major depression. The treatment response accumulates to a clinically meaningful level over 4 to 6 weeks of active treatment.

(Am J Psychiatry 2006; 163:88-94)

$\mathrm{M}$ significant percentage of patients fail to respond to standard therapies (1). Over the last 10 years, a number of clinical trials of repetitive transcranial magnetic stimulation (rTMS) for treatment-resistant depressive illness have been conducted (e.g., see references 2-6). Most of these trials used high-frequency rTMS, usually between 5 and 20 $\mathrm{Hz}$, applied to the left dorsolateral prefrontal cortex. More recently, an alterative paradigm, involving the provision of low-frequency stimulation to the right dorsolateral prefrontal cortex, has also been shown to have antidepressant activity $(7,8)$. Low- and high-frequency stimulation are proposed to have opposite effects on cortical activity, possibly underlying these clinical findings (7). However, although most of these studies have shown that the antidepressant effects of active rTMS are greater than those of sham stimulation, these differences have been of limited magnitude, and considerable questions remain as to whether rTMS has clinically relevant effects $(9,10)$.

Despite the evidence for the efficacy of both left- and right-side stimulation, the effectiveness of sequentially combining these two forms of stimulation has not been rigorously evaluated in studies with substantial group sizes. Therefore, we conducted a randomized, doubleblind, sham-controlled trial of the efficacy of sequential "bilateral" rTMS, sequentially combining both high-frequency left-side stimulation with low-frequency rightside rTMS. We hypothesized that bilateral active rTMS would produce a greater therapeutic effect than sham stimulation with no significant cognitive side effects. In addition to combining the two forms of rTMS, we also provided treatment for up to 6 weeks.

\section{Method}

\section{Study Design}

The study involved a two-arm, double-blind, randomized, controlled trial ( $\mathrm{N}=25$ in each group) (Figure 1). The patients were sequentially randomly assigned to groups with a single randomnumber sequence (no stratification) that was used to produce a series of sealed envelopes. The envelope for each patient was opened immediately before commencement of the first treatment session by the clinician administering the rTMS after the administration of the baseline assessment. The patients and raters were blind to treatment, but the clinician administering the rTMS was aware of the treatment group. 
All patients initially received 10 sessions of treatment on a daily basis, 5 days per week. After the 10th session, a blind assessment was made. At this time, the patients were classified as "initial responders" if they had achieved a $>20 \%$ reduction in score on the Montgomery-Åsberg Depression Rating Scale (MADRS) (11). If this was the case, they were offered a further week of rTMS. After week 2 , the patients were assessed weekly by a blinded rater. Continued participation in the study was dependent on the patient's, achieving a further $10 \%$ reduction in MADRS score at each of these weekly assessments, up to a maximum of 6 weeks of total treatment. At any assessement, patients who were not responding were withdrawn from the study, and if they had received sham stimulation, they were offered open-label active rTMS under the same treatment conditions (assessment at 2 weeks and weekly thereafter).

\section{Subjects}

Fifty patients with a DSM-IV diagnosis of major depression participated in the study (Table 1). The patients were recruited from the outpatient department of a public regional mental health service and by referral from a number of private psychiatrists between January 2003 and September 2004. Fifty-six patients were originally screened; six were excluded before random assignment because of insufficient depression severity (3) or comorbidity (3). All patients were outpatients during the trial. The study was powered (0.93) to show an 8-point difference in the study endpoint variable between the groups (alpha $<0.05$, sigma $=$ 8).

The treating psychiatrist and a study psychiatrist (P.B.F.) assigned a DSM-IV diagnosis to each patient. Forty-two patients had a diagnosis of major depressive episode, and eight had a diagnosis of bipolar I disorder, depressive episode (four in each group).

All patients scored greater than 20 on the MADRS (mean=33.6, $\mathrm{SD}=7.8$ ). Patients with significant medical illnesses, neurological disorders, or other axis I psychiatric disorders were excluded. All patients had failed to respond to a minimum of two courses of antidepressant medications for at least 6 weeks (stage II, definition of Thase and Rush [12]) (mean number of lifetime courses=5.9, SD= 3.0). These courses were required to be at a standard minimum effective dose, such as $20 \mathrm{mg}$ /day of fluoxetine, paroxetine, or citalopram; $150 \mathrm{mg} /$ day of a tricyclic antidepressant; or $125 \mathrm{mg} /$ day of venlafaxine (1). The patients were not deliberately withdrawn from medication before the trial; however, their doses were not allowed to have changed in the 4 weeks before the commencement of the study or during the trial. The number of medications each group was taking are presented in Table 1 . There was no difference in the proportions of patients taking any of the medication types between the two groups. Twenty patients reported at least one previous ECT treatment course. Half of these patients reported a previously favorable response to ECT, seven reported no response, and three reported a course limited by cognitive side effects. Three of the patients were left-handed (two in the active group and one in the sham group) ( $p>0.05$, Fisher's exact test).

After a complete description of the study had been given to the subjects, written informed consent was obtained from all patients on a form approved by Alfred Hospital's Human Research and Ethics Committee.

\section{rTMS Treatment}

rTMS was administered with a Medtronic Magpro30 magnetic stimulator (Medtronic Inc., Minneapolis) with stand-held 70-mm figure eight coils. There was limited interaction with the subject during the rTMS sessions. At all times, the coil was held tangentially to the scalp with the handle pointing back and away from the midline at $45^{\circ}$. The site of stimulation during the rTMS treatment sessions was defined by a point $5 \mathrm{~cm}$ anterior to that required for maximum stimulation of the abductor pollicis brevis
FIGURE 1. Study Design Showing Subjects With TreatmentResistant Depression Who Were Randomly Assigned to Sham Stimulation $(\mathrm{N}=25)$ or Active Treatment $(\mathrm{N}=25)$ and Entered the Study's Extension Phase

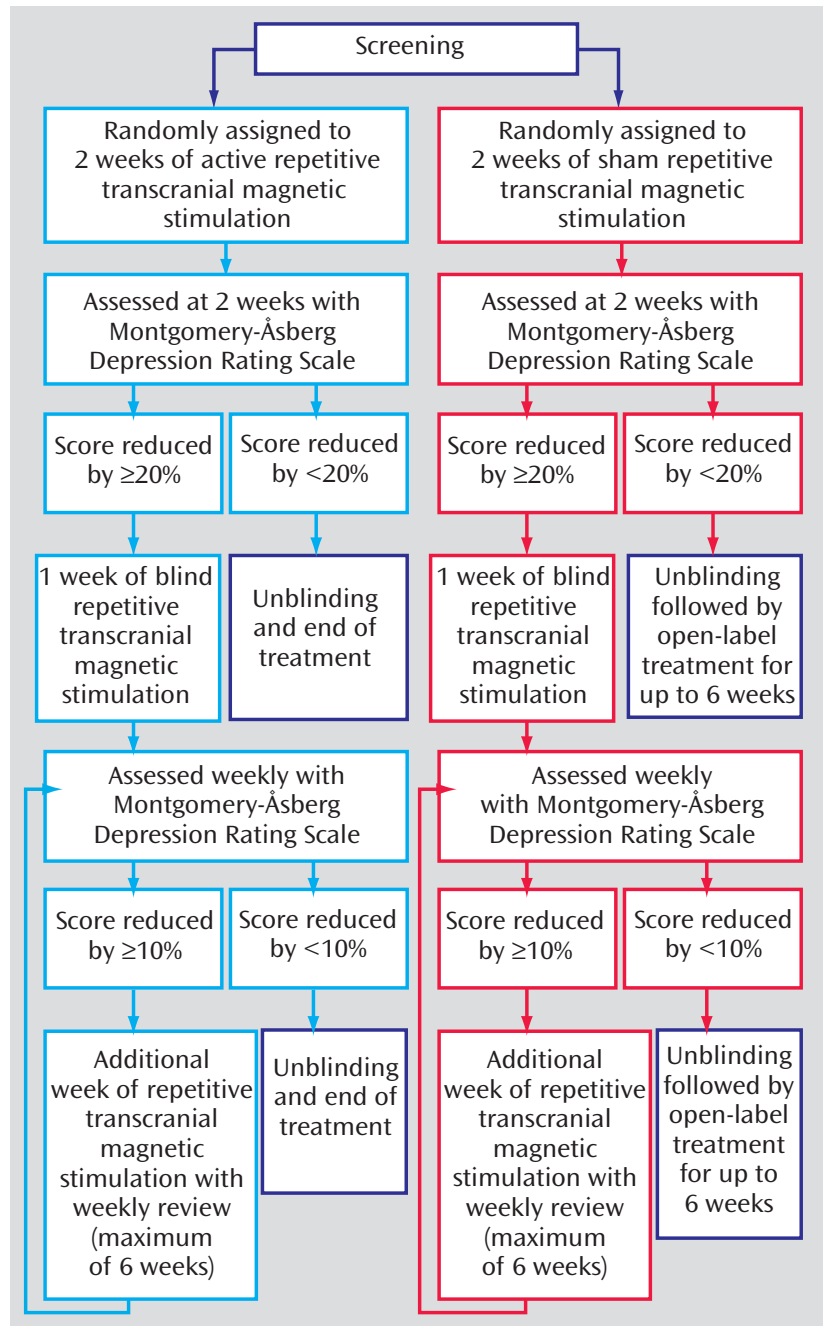

muscle. The resting motor threshold was measured bilaterally with standard electromyogram methods (13).

Treatment stimulation was sequential: to the right and then the left dorsolateral prefrontal cortex. Right-side stimulation was applied at $1 \mathrm{~Hz}$ in three trains of 140 seconds' duration with a 30second interval between the trains. It was applied at $110 \%$ of the resting motor threshold. Left-side stimulation was applied at 10 $\mathrm{Hz}$ in 15 trains of 5 seconds' duration with a 25-second intertrain interval. Left-side stimulation was applied at $100 \%$ of the resting motor threshold. This resulted in an imbalance in the number of pulses per side but an approximately equal time of administration. Provision of a longer duration of $1-\mathrm{Hz}$ stimulation was not judged to be feasible at the time of study initiation. One-Hz stimulation was provided at a higher intensity because, in our experience, it is better tolerated by subjects.

Sham stimulation was applied with stimulation parameters identical to those for the active treatment (on both sides) but with the coil angled at $45^{\circ}$ off the head. The medial wing of the coil was resting on the scalp. This produced some degree of scalp sensation in most participants but has been shown to produce a limited degree of intracortical activity $(14,15)$. At the completion of each phase of treatment, the patients were asked whether they 
TABLE 1. Demographic and Baseline Clinical Characteristics of Subjects Receiving Active Treatment or Sham Stimulation for Treatment-Resistant Depression

\begin{tabular}{|c|c|c|c|c|c|c|c|}
\hline \multirow[t]{2}{*}{ Characteristic } & \multirow{2}{*}{\multicolumn{2}{|c|}{$\frac{\text { Active Treatment }}{\mathrm{N}}$}} & \multirow{2}{*}{\multicolumn{2}{|c|}{$\begin{array}{l}\text { Sham Stimulation } \\
\mathrm{N}\end{array}$}} & \multicolumn{3}{|c|}{ Analysis } \\
\hline & & & & & $\chi^{2}$ & $\mathrm{df}$ & $p$ \\
\hline Sex & & & & & 0.09 & 1 & 0.77 \\
\hline Male & 10 & & 9 & & & & \\
\hline Female & 15 & & 16 & & & & \\
\hline Diagnosis & & & & & -0.004 & 1 & 0.95 \\
\hline Unipolar & 21 & & 21 & & & & \\
\hline Bipolar & 4 & & 4 & & & & \\
\hline \multicolumn{8}{|l|}{ Antidepressant medication } \\
\hline Selective serotonin reuptake inhibitor & 12 & & 9 & & & & \\
\hline Serotonin norepinephrine reuptake inhibitor & 3 & & 6 & & & & \\
\hline Tricyclics & 5 & & 5 & & & & \\
\hline Other & 3 & & 1 & & & & \\
\hline None & 2 & & 4 & & & & \\
\hline \multicolumn{8}{|l|}{ Mood stabilizers } \\
\hline Lithium & 2 & & 2 & & & & \\
\hline Anticonvulsants & 3 & & 4 & & & & \\
\hline None & 20 & & 18 & & & & \\
\hline Antipsychotic medication & 6 & & 8 & & & & \\
\hline \multirow[t]{2}{*}{ Daily use of benzodiazepines } & 6 & & 10 & & & & \\
\hline & Mean & SD & Mean & SD & $\mathrm{t}$ & df & $\mathrm{p}$ \\
\hline Age (years) & 46.8 & 10.7 & 43.7 & 10.2 & 1.06 & 48 & 0.30 \\
\hline Age at onset (years) & 30.4 & 13.8 & 25.2 & 11.4 & $1.40^{\mathrm{a}}$ & 47 & 0.17 \\
\hline Number of episodes & 3.8 & 3.6 & 4.4 & 4.3 & -0.58 & 48 & 0.56 \\
\hline Duration of current episode (months) & 7.2 & 10.9 & 6.1 & 7.9 & 0.48 & 48 & 0.63 \\
\hline Number of failed antidepressant trials & 5.6 & 3.1 & 6.2 & 3.0 & $-0.64^{\mathrm{a}}$ & 47 & 0.52 \\
\hline Montgomery-Åsberg Depression Rating Scale score & 34.0 & 5.6 & 34.2 & 5.2 & -0.33 & 48 & 0.74 \\
\hline Hamilton Depression Rating Scale score & 22.5 & 7.4 & 19.8 & 4.4 & 1.20 & 48 & 0.22 \\
\hline Beck Depression Inventory score & 29.2 & 9.6 & 29.3 & 9.7 & -0.01 & 48 & 0.99 \\
\hline Brief Psychiatric Rating Scale score & 19.4 & 5.6 & 19.8 & 4.3 & -0.28 & 48 & 0.78 \\
\hline Global Assessment of Functioning Scale score & 48.8 & 8.2 & 49.0 & 4.9 & -0.08 & 48 & 0.94 \\
\hline CORE Rating of Psychomotor Disturbance & 9.0 & 4.1 & 8.4 & 4.8 & 0.50 & 48 & 0.61 \\
\hline
\end{tabular}

${ }^{a}$ Data are missing for one subject.

thought they had received active or sham stimulation. They were asked to guess "yes" or "no."

\section{Clinical Assessment}

The primary outcome measure for the study was score on the MADRS. The patients were assessed with the MADRS, the 17-item version of the Hamilton Depression Rating Scale (HAM-D), the Beck Depression Inventory (BDI), the Brief Psychiatric Rating Scale (BPRS), the CORE Rating of Psychomotor Disturbance (16), and the Global Assessment of Functioning (GAF) Scale (DSM-IVTR). Ratings at follow-up were also made with the Clinical Global Impression (CGI) improvement subscale. Handedness was recorded with the Edinburgh Inventory (17). The ratings were made by clinically trained raters who were required to demonstrate adequate interrater reliability $\left(r^{2}>0.9\right)$.

A brief cognitive assessment was made at each visit with the following tests, predominately focusing on memory performance: the Hopkins Verbal Learning Test (18), the Controlled Oral Word Association Test (19), the WAIS digit span (forward and backward), the Brief Visuospatial Memory Test-Revised (20), and the Visuospatial Digit Span (21).

\section{Data Analysis}

$\mathrm{T}$ tests and chi-square tests were used to investigate differences between the groups on demographic and baseline clinical variables. Two primary analyses were conducted with repeated-measures analysis of variance (ANOVA) with the last-observation-carried-forward method (intention to treat) on the MADRS data, response at 2 weeks, and response across all study assessments (significance at $\mathrm{p}<0.025)$. A secondary series of models was com- puted to include potential covariates, such as age, sex, diagnosis, and medication status (use of antidepressants, mood stabilizers, and antipsychotics as separate covariates). Post hoc paired t tests were used to analyze changes in scores between different study visits (significance at $\mathrm{p}<0.0125$ ). In addition, the percentage of patients meeting response criteria ( $>50 \%$ reduction in MADRS score) and remission criteria (final MADRS score of $<10$ [22]) were compared with Fisher's exact test.

Repeated-measures ANOVA models were also used to analyze group differences for BDI and HAM-D scores. Changes in scores from baseline to final study visit were calculated for the BPRS, the GAF, and the CGI and compared between the groups. Pearson's correlation coefficients were calculated to assess potential predictors of clinical response. Because these were limited to one measure, planned linear regression analysis was not conducted.

The cognitive data were analyzed with paired t tests comparing the baseline and endpoint scores. Separate analyses were conducted for the two groups as a whole. When a difference was seen in the basic analysis, a two-way ANOVA model was computed with time and group as the two factors.

All procedures were two-tailed, and unless otherwise stated, significance was set at an alpha level of 0.05 . All analyses were conducted with SPSS 11.5 (Chicago, SPSS).

\section{Results}

\section{Patients}

Baseline clinical characteristics are summarized in Table 1 . There were no significant baseline differences be- 
TABLE 2. Treatment Response by Montgomery-Åsberg Depression Rating Scale (MADRS) and Beck Depression Inventory (BDI) Scores at Each Assessment for Subjects Receiving Active Treatment or Sham Stimulation for Depression

\begin{tabular}{|c|c|c|c|c|}
\hline \multirow[b]{2}{*}{ Time and Group } & \multicolumn{2}{|c|}{ MADRS Score } & \multicolumn{2}{|c|}{ BDI Score } \\
\hline & Mean & SD & Mean & SD \\
\hline \multicolumn{5}{|l|}{ Baseline } \\
\hline Active $(\mathrm{N}=25)$ & 34.0 & 5.9 & 29.2 & 18.3 \\
\hline Sham $(N=25)$ & 34.1 & 5.2 & 29.3 & 9.9 \\
\hline \multicolumn{5}{|l|}{ Week 2} \\
\hline Active $(\mathrm{N}=25)$ & 26.2 & 10.2 & 18.3 & 10.3 \\
\hline Sham $(N=22)$ & 30.9 & 8.2 & 21.6 & 13.7 \\
\hline \multicolumn{5}{|l|}{ Week 3} \\
\hline Active $(\mathrm{N}=15)$ & 18.7 & 8.7 & 14.1 & 8.8 \\
\hline Sham $(N=7)$ & 29.6 & 11.7 & 18.8 & 14.4 \\
\hline \multicolumn{5}{|l|}{ Week 4} \\
\hline Active $(\mathrm{N}=13)$ & 11.7 & 7.1 & 10.5 & 8.3 \\
\hline Sham $(N=2)$ & 34.5 & 12.0 & 21.0 & 19.8 \\
\hline Week 5: active $(\mathrm{N}=11)^{\mathrm{a}}$ & 11.1 & 6.9 & 10.0 & 6.8 \\
\hline Week 6: active $(\mathrm{N}=11)^{\mathrm{a}}$ & 8.9 & 7.9 & 9.2 & 6.7 \\
\hline
\end{tabular}

${ }^{a}$ There were no patients in the sham group at weeks 5 and 6 .

tween the groups. Of the 50 patients randomly assigned to groups, three (all in the sham group) failed to complete the initial 2-week treatment period. One patient withdrew consent before undergoing the first treatment session, and two patients withdrew during treatment; both had experienced no change or a mild degree of clinical deterioration before withdrawal.

\section{Primary Outcome Analysis}

In the first 2 weeks of the trial, there was a mean improvement on the MADRS of $7.7(\mathrm{SD}=7.1)$ in the active group and $3.2(\mathrm{SD}=7.7)$ in the sham group $(\mathrm{F}=25.5, \mathrm{df}=1,25$, $\mathrm{p}<0.001$ ). In the active group, 10 (of 25 patients) finished after 2 weeks, two continued for 3 weeks, two for 4 weeks, and 11 for the full 6 weeks (Table 2). In the sham group, only seven continued for longer than 2 weeks. Two of these continued into week 4 , but none progressed further than week 4 in the study. Over all study visits, there was a significant effect of time $(\mathrm{F}=4.8, \mathrm{df}=5,44, \mathrm{p}=0.001)$ and a significant group-by-time interaction ( $\mathrm{F}=3.9, \mathrm{df}=5,44, \mathrm{p}=0.005)$, indicating a greater reduction in MADRS scores in the active group than in the sham group (Figure 2). On post hoc $t$ tests, the reduction in MADRS scores was significant for the active group between baseline and week $2(\mathrm{p}<0.001)$, weeks 3 and $4(\mathrm{p}<0.001)$, and weeks 5 and $6(\mathrm{p}=0.01)$. The differences between weeks 2 and $3(\mathrm{p}=0.08)$ and weeks 4 and $5(\mathrm{p}=0.05)$ only approached significance. For the sham group, there was a reduction in MADRS scores that approached significance between baseline and week $2(\mathrm{p}=$ 0.06 ) but not between other study visits.

By the study end, 11 patients (44\%) in the active group and two patients (8.0\%) in the sham group met criteria for clinical response $(\mathrm{p}<0.05)$. An additional five patients in the active (and two in the sham) group achieved an improvement of between $25 \%$ and $50 \%$ on the MADRS. Nine patients $(36 \%)$ in the active group and no patients in the sham group met the criteria for clinical remission $(\mathrm{p}=$
FIGURE 2. Total Scores on the Montgomery-Åsberg Depression Rating Scale for Depressed Subjects Receiving Sham Stimulation or Active Treatment at Each Assessment for Intent-to-Treat, Last-Observation-Carried-Forward Data

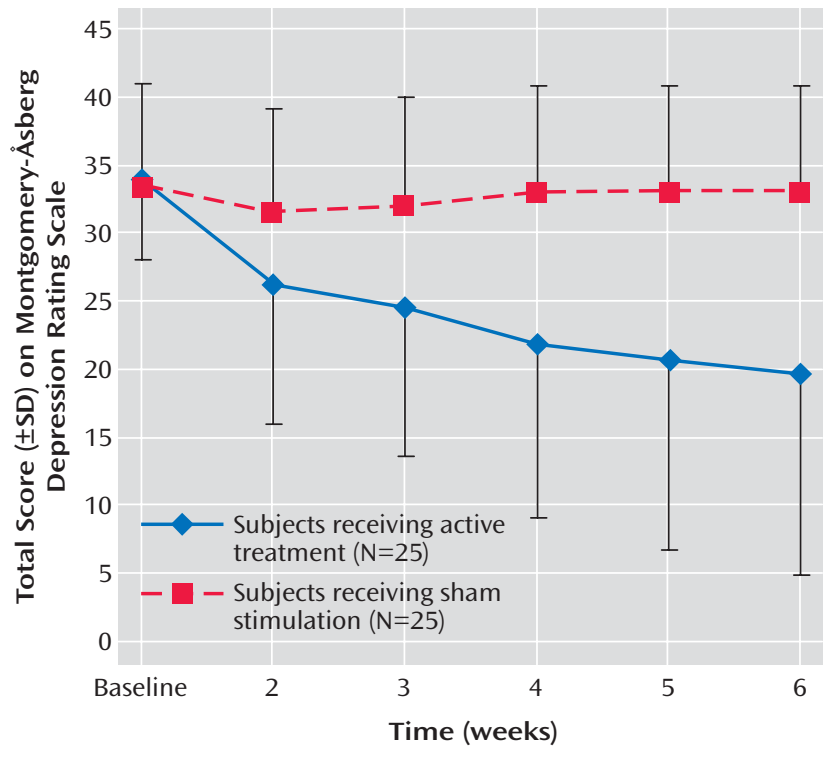

0.005), and five of these patients had MADRS scores of 4 or below.

The primary efficacy analysis was repeated with models controlling for age, sex, diagnosis, and treatment with any antidepressant, mood stabilizer, benzodiazepine, or antipsychotic medication as covariates. The effect of group remained significant, and there were no other significant effects.

\section{Secondary Outcome Analyses}

The repeated-measures ANOVA analysis was also conducted for BDI scores. There also was a significant difference between the two groups (group-by-time interaction: $\mathrm{F}=3.2, \mathrm{df}=5,44, \mathrm{p}=0.01$ ). There was no effect of potential covariates.

Total changes in HAM-D scores were compared (baseline to final study visit). There was a significantly greater improvement in the active group (mean $=45.2 \%, \mathrm{SD}=40.1 \%$ ) versus the sham group (mean $=5.4 \%, \mathrm{SD}=23.1 \%)(\mathrm{t}=4.3, \mathrm{df}=$ $38.4, \mathrm{p}<0.001)$. Thirteen patients (52\%) in the active group and two patients $(8 \%)$ in the sham group experienced a $>50 \%$ reduction in HAM-D scores $\left(\chi^{2}=11.5, \mathrm{df}=1, \mathrm{p}=0.001\right)$. Ten patients $(40 \%)$ in the active group met HAM-D criteria for remission $(<8)$ by the study end (Table 3 ). There was a significantly greater improvement in total BPRS scores in the active group (mean $=41.5 \%, \mathrm{SD}=38.5 \%$ ) versus in the sham group $($ mean $=8.2 \%, \mathrm{SD}=30.7 \%)(\mathrm{t}=3.4, \mathrm{df}=45.7, \mathrm{p}=$ $0.001)$. There were also significant differences in scores at the end of the study on the CGI Scale for illness severity (mean $=3.4, \mathrm{SD}=1.6$, versus mean $=4.4, \mathrm{SD}=0.7)(\mathrm{t}=-2.9, \mathrm{df}=$ 33.0, $\mathrm{p}<0.01$ ), the CGI Scale for improvement (mean $=3.3$, $\mathrm{SD}=1.2$, versus mean $=4.0, \mathrm{SD}=1.4)(\mathrm{t}=-2.1, \mathrm{df}=45, \mathrm{p}<0.05)$, 
TABLE 3. Response and Remission Rates ${ }^{\mathrm{a}}$ by the Montgomery-Åsberg Depression Rating Scale (MADRS) and the Hamilton Depression Rating Scale (HAM-D) for Subjects Receiving Active or Sham Stimulation for Depression

\begin{tabular}{|c|c|c|c|c|c|c|c|c|}
\hline \multirow[b]{3}{*}{ Session } & \multicolumn{4}{|c|}{ MADRS } & \multicolumn{4}{|c|}{ HAM-D } \\
\hline & \multicolumn{2}{|c|}{$\begin{array}{c}\text { Response } \\
\text { Rate }\end{array}$} & \multicolumn{2}{|c|}{$\begin{array}{l}\text { Remission } \\
\text { Rate }\end{array}$} & \multicolumn{2}{|c|}{$\begin{array}{c}\text { Response } \\
\text { Rate }\end{array}$} & \multicolumn{2}{|c|}{$\begin{array}{l}\text { Remission } \\
\text { Rate }\end{array}$} \\
\hline & $\mathrm{N}$ & $\%$ & $\mathrm{~N}$ & $\%$ & $\mathrm{~N}$ & $\%$ & $\mathrm{~N}$ & $\%$ \\
\hline 1 & 3 & 12 & 2 & 8 & 5 & 20 & 4 & 16 \\
\hline 2 & 1 & 4 & 0 & 3 & 12 & 2 & 8 & \\
\hline 3 & 4 & 16 & 3 & 12 & 9 & 36 & 6 & 24 \\
\hline 4 & 2 & 8 & 0 & 2 & 8 & 2 & 8 & \\
\hline 5 & 10 & 40 & 5 & 20 & 10 & 40 & 7 & 28 \\
\hline 6 & 2 & 8 & 0 & 1 & 4 & 1 & 4 & \\
\hline 7 & 11 & 44 & 9 & 36 & 10 & 40 & 10 & 40 \\
\hline 8 & 2 & 8 & 0 & 1 & 4 & 1 & 4 & \\
\hline 9 & 11 & 44 & 9 & 36 & 13 & 52 & 10 & 40 \\
\hline 10 & 2 & 8 & 0 & 1 & 4 & 1 & 4 & \\
\hline
\end{tabular}

${ }^{a}$ Response rate was calculated as the number and percent of patients meeting response criteria ( $>50 \%$ reduction in MADRS and HAM-D scores) at each time point per group. Remission rate was calculated as the number and percent of patients meeting remission criteria (MADRS score $<10$, HAM-D score $<8$ ) at each time point per group.

and the GAF Scale (mean $=59.0, \mathrm{SD}=16.5$, versus mean $=50.1$, $\mathrm{SD}=10.3)(\mathrm{t}=2.0, \mathrm{df}=40.2, \mathrm{p}<0.05)$.

\section{Crossover Data}

Eighteen of the patients in the sham group went on to receive at least 2 weeks of active treatment (seven had 2 weeks, one had 3 weeks, three had 4 weeks, two had 5 weeks, and five had 6 weeks). The mean improvement in MADRS scores was $37.0 \%(\mathrm{SD}=43.7 \%)(\mathrm{t}=3.7, \mathrm{df}=17$, $\mathrm{p}<0.005)$. Eight of the patients experienced a $>50 \%$ reduction in MADRS scores, and six met remission criteria at the study end.

\section{Predictors of Response}

Clinical response (change in MADRS scores) was analyzed for the active treatment group and the patients who crossed over to active treatment after sham stimulation (pooled). There was an inverse relationship between the severity of melancholic symptoms and response (total CORE Rating of Psychomotor Disturbance: $\mathrm{r}^{2}=-0.33, \mathrm{~N}=$ 43, $\mathrm{p}<0.05$; CORE noninteractiveness subscale score: $\mathrm{r}^{2}=$ $-0.34, \mathrm{~N}=43, \mathrm{p}<0.05)$. No other variables correlated with response, including the number of trials of previous antidepressant medications. There was no relationship between previous ECT response and response to rTMS ( $\mathrm{p}=$ 0.76 , Fisher's exact test).

There was no correlation between the degree of clinical response and the degree of psychotic symptoms (total BPRS score: $\mathrm{r}^{2}=-0.07, \mathrm{p}>0.05$; BPRS thought disturbance subscale score: $\mathrm{r}^{2}=0.14, \mathrm{p}>0.05$; BPRS suspiciousness subscale score: $\left.\mathrm{r}^{2}=0.03, \mathrm{p}>0.05\right)$. Six patients scored $>3$ at baseline on the thought disturbance subscale. Four received active treatment, and two met response criteria. Seven patients scored $>3$ at baseline on the suspiciousness subscale. Five received active treatment, and two met response criteria. In regard to diagnosis, two of four patients with bipolar disorder met response criteria in the active group and one of four in the sham group.

\section{Integrity of Blinding}

The blinding of the patients was maintained in the trial as assessed at the 2 -week assessment time point. A similar percentage of patients in each group (15 in the active group and 11 of 22 patients in the sham group) guessed that they were in the active group when asked at 2 weeks into the treatment $\left(\chi^{2}=0.47, \mathrm{df}=1, \mathrm{p}>0.05\right)$, and the same number of subjects correctly guessed their treatment in each group. However, of the patients who were classified as responders at the trial end, most (12 of 13) had guessed that they were in the active group at week 2 (nine of 11 in the active group and two of two patients in the sham group). This reflected the fact that clinical response was the major reason given for the guess. Factors having to do with the strength of the experienced somatic sensations were not raised as a significant issue by the patients.

\section{Side Effects}

Five patients in the active group and two patients in the sham group reported a headache persisting for longer than 10 minutes after one or more treatment sessions. Three patients in the active group (none in the sham) reported feeling nauseated after one or more treatment sessions. This was relatively brief in all cases. There were no significant adverse events, including seizures or induced manic episodes.

\section{Cognition}

No significant reduction in cognitive performance was seen for any subject. Performance decreased on the Hopkins Verbal Learning Test delayed recall subscale for both active and sham groups, with no group-by-time interaction $(\mathrm{F}=0.09, \mathrm{df}=1,45, \mathrm{p}>0.05)$. Performance improved on the digit span backward test in the active group only (group-by-time interaction: $\mathrm{F}=3.4, \mathrm{df}=1,44, \mathrm{p}=0.07$ ) and on the Controlled Oral Word Association Test for both groups (time effect: $\mathrm{F}=13.5, \mathrm{df}=1,45, \mathrm{p}=0.001$ ). For the active treatment group, improved MADRS scores did not correlate with improved performance on the digit span backward test $\left(\mathrm{r}^{2}=-0.36, \mathrm{p}>0.05\right)$.

\section{Discussion}

This double-blind, sham-controlled, parallel-group trial found a significant therapeutic benefit of sequentially applied bilateral rTMS in patients with treatmentresistant depressive illness. We found that rTMS produced a therapeutic response that was evident by 2 weeks into the trial and progressively increased for a total of 6 weeks. Most critically, a significant therapeutic response was achieved by about half of the patients in the active treatment group, and a significant proportion of patients achieved clinical remission. 
The response rate for patients in this study was greater than the vast majority of published reports of rTMS treatment in depression and of a degree that we consider clinically relevant and applicable. This is in spite of the selection of a relatively heterogeneous group of patients with a marked degree of treatment resistance. Of importance, this is the first rTMS study to show a clinically significant percentage of patients achieving remission criteria. Cohen et al. (23) published a case series showing significant benefit for four of seven patients treated with similar treatment parameters. Hausmann et al. (24) compared a group of patients also receiving high-frequency left-side and low-frequency right-side stimulation to unilateral-side rTMS and a sham group and showed no differences among all three groups. However, the size per group was considerably smaller than in our study, the patients were treated for a total of only 2 weeks, and new antidepressant medication was commenced concurrently with the rTMS-all confounding interpretation. The same group had also previously compared high-frequency left to bilateral (high-frequency left and low-frequency right) stimulation, but the capacity of this study to show differences between active stimulation groups was also limited by its size (25).

It is not clear why the response rate in this trial was significantly greater than in previous studies of rTMS, but combining the two treatment types could potentially enhance response in several ways. First, it is possible that some patients have left-side treatment-responsive depression and some have right-side treatment-responsive depression. Therefore, by giving everyone both treatments, we maximized the likelihood of a treatment response in any individual patient. This should ensure the maximal number of treatment responders. Second, it is notable that despite providing more pulses on the left, we actually gave more right-side pulses (420 versus 300 ) at a higher intensity ( $110 \%$ versus $100 \%$ of the resting motor threshold) than in previous studies. Therefore, it is possible that our improved results compared to our previous study (7) came about because of the greater degree of right-side stimulation alone. However, given the well-established antidepressant properties of high-frequency left-side rTMS, this seems somewhat doubtful. Alternatively, the two treatments may have a synergistic effect in likely treatment responders. Theoretically, this also seems quite plausible given that unilateral stimulation can produce effects bilaterally (26). However, it is possible that the greater benefits seen with rTMS in this study did not relate to the combination of the two types of treatment but arose purely from the increased duration of treatment provided as stimulation for 6 weeks although it has not previously been investigated. In support of this, we saw progressive decreases in depression severity across the full 6 weeks of the study in the active group. However, because the rates of response at 4 weeks were already quite good compared to the response rates in previous studies, such as our own, we cannot definitely conclude that the response rate was purely an effect of longer treatment dura- tion (7). These issues will only be resolved with a large randomized trial comparing unilateral and bilateral approaches.

There are a number of important limitations, including, first, our method of only continuing subjects in treatment who reported ongoing clinical improvement at weekly assessments. With this design, it is possible that patients may have been removed from the study who could have had a slower or less steady progression in improvement in their depressive symptoms. However, we considered before commencement of the trial that this was more likely to lessen the difference between active treatment and sham stimulation than to enhance it because it would potentially remove true active treatment responders prematurely, although it is possible that it could exclude slow sham responders. Given the results of previous studies, we were surprised by the degree of difference in the persistence of the clinical effects, and as such, the high degree of dropouts makes the last-observation-carried-forward ANOVA models potentially unreliable. However, we have presented this as our a priori analysis plan. Despite these concerns, the supporting analyses, for example, showing the significant difference in clinical response at 2 weeks, clearly indicate the superiority of the active treatment over the sham stimulation.

We also do not have good information as to the integrity of the blinding after 2 weeks of treatment, and the clinicians providing treatment were not blind to group. However, the blinding was adequately maintained at 2 weeks, and the majority of the sham responders who deteriorated and then came out of the study did so in the week immediately after this assessment. There is no de novo reason to assume that they would have been unblinded in this period of time because none of the other study practices, for example, the methods of treatment administration, altered. In addition, the study adds minimal information on the potential predictors of response to rTMS. We did find a weak inverse relationship with melancholic symptoms, which is not consistent with the positive relationship we found in our previous study (7). Larger trials powered specifically to address this question will be required.

Finally, interpretation of the results of this study is complicated by the concurrent medication treatment of most subjects. Given that the majority of the study subjects were receiving medication, it is essentially an add-on study design. However, all subjects had been taking stable doses of medication for at least a month (usually much longer), were not improving before the trial, and had a high degree of treatment resistance. The relatively low sham rate of response also confirms that the degree of response in the active group was unlikely to be attributable to concurrent medication treatment, although it is possible that there was a synergistic interaction between rTMS and antidepressant medication.

In conclusion, sequential bilateral rTMS combining high-frequency left-side and low-frequency right-side 
treatment appears to be a promising antidepressant strategy for treatment-resistant depressive illness. Bilateral rTMS applied over 6 weeks induces clinically meaningful responses, including clinical remission in a clinically relevant subgroup of patients, and is superior to sham stimulation.

Received Feb. 23, 2005; revision received April 5, 2005; accepted April 26, 2005. From the Alfred Psychiatry Research Centre, the Alfred and Monash University Department of Psychological Medicine; and the Centre for Addiction and Mental Health Clarke Division, Toronto. Address correspondence and reprint requests to Dr. Fitzgerald, Alfred Psychiatry Research Centre, Alfred and Monash University, Old Baker Bldg., First Fl., Commercial Rd., Melbourne, Victoria, Australia, 3004; paul.fitzgerald@med.monash.edu.au (e-mail).

Supported by grant 143651 from the Australian National Health and Medical Research Council and by Constance and Stephen Lieber through a National Alliance for Research on Schizophrenia and Depression Lieber Young Investigator award (to Dr. Fitzgerald).

The authors thank the patients whose participation was essential to the study and Dr. Kerrie Chappell who assisted with the repetitive transcranial magnetic stimulation.

\section{References}

1. Fava M: Diagnosis and definition of treatment-resistant depression. Biol Psychiatry 2003; 53:649-659

2. George MS, Wassermann EM, Williams WA, Callahan A, Ketter TA, Basser P, Hallett M, Post RM: Daily repetitive transcranial magnetic stimulation (rTMS) improves mood in depression. Neuroreport 1995; 6:1853-1856

3. Berman RM, Narasimhan M, Sanacora G, Miano AP, Hoffman RE, Hu XS, Charney DS, Boutros NN: A randomized clinical trial of repetitive transcranial magnetic stimulation in the treatment of major depression. Biol Psychiatry 2000; 47:332-337

4. George MS, Nahas Z, Molloy M, Speer AM, Oliver NC, Li XB, Arana GW, Risch SC, Ballenger JC: A controlled trial of daily left prefrontal cortex TMS for treating depression. Biol Psychiatry 2000; 48:962-970

5. Grunhaus L, Schreiber S, Dolberg OT, Polak D, Dannon PN: A randomized controlled comparison of electroconvulsive therapy and repetitive transcranial magnetic stimulation in severe and resistant nonpsychotic major depression. Biol Psychiatry 2003; 53:324-331

6. Padberg F, Zwanzger P, Thoma H, Kathmann N, Haag C, Greenberg BD, Hampel H, Moller HJ: Repetitive transcranial magnetic stimulation (rTMS) in pharmacotherapy-refractory major depression: comparative study of fast, slow and sham rTMS. Psychiatry Res 1999; 88:163-171

7. Fitzgerald PB, Brown T, Marston NAU, Daskalakis ZJ, Kulkarni J: A double-blind placebo controlled trial of transcranial magnetic stimulation in the treatment of depression. Arch Gen Psychiatry 2003; 60:1002-1008

8. Klein E, Kreinin I, Chistyakov A, Koren D, Mecz L, Marmur S, Ben-Shachar D, Feinsod M: Therapeutic efficacy of right prefrontal slow repetitive transcranial magnetic stimulation in major depression: a double-blind controlled study. Arch Gen Psychiatry 1999; 56:315-320

9. Burt T, Lisanby SH, Sackeim HA: Neuropsychiatric applications of transcranial magnetic stimulation: a meta analysis. Int J Neuropsychopharmacol 2002; 5:73-103
10. Martin JL, Barbanoj MJ, Schlaepfer TE, Thompson E, Perez V, Kulisevsky J: Repetitive transcranial magnetic stimulation for the treatment of depression: systematic review and meta-analysis. Br J Psychiatry 2003; 182:480-491

11. Montgomery SA, Åsberg M: A new depression scale designed to be sensitive to change. Br J Psychiatry 1979; 134:382-389

12. Thase ME, Rush AJ: When at first you don't succeed: sequential strategies for antidepressant nonresponders. J Clin Psychiatry 1997; 58(suppl 13):23-29

13. Pridmore S, Fernandes Filho JA, Nahas Z, Liberatos C, George MS: Motor threshold in transcranial magnetic stimulation: a comparison of a neurophysiological method and a visualization of movement method. J ECT 1998; 14:25-27

14. Lisanby SH, Gutman D, Luber B, Schroeder C, Sackeim HA: Sham TMS: intracerebral measurement of the induced electrical field and the induction of motor-evoked potentials. Biol Psychiatry 2001; 49:460-463

15. Loo CK, Taylor JL, Gandevia SC, McDarmont BN, Mitchell PB, Sachdev PS: Transcranial magnetic stimulation (TMS) in controlled treatment studies: are some "sham" forms active? Biol Psychiatry 2000; 47:325-331

16. Parker G, Hadzi-Pavlovic D, Boyce P, Wilhelm K, Brodaty H, Mitchell P, Hickie I, Eyers K: Classifying depression by mental state signs. Br J Psychiatry 1990; 157:55-65

17. Oldfield RC: The assessment and analysis of handedness: the Edinburgh Inventory. Neuropsychologia 1971; 9:97-113

18. Shapiro AM, Benedict RH, Schretlen D, Brandt J: Construct and concurrent validity of the Hopkins Verbal Learning Test-Revised. Clin Neuropsychol 1999; 3:348-358

19. Benton A, Hamsher K: Multilingual Aphasia Examination. Iowa City, AJA Associates, 1989

20. Benedict RH, Schretlen D, Groninger L, Dobraska M, Shpritz B: Revision of the Brief Visuospatial Memory Test: studies of normal performance, reliability, and validity. Psychological Assessment 1996; 8:145-153

21. Wechsler D: The measurement of adult intelligence. Baltimore, Williams \& Wilkins, 1939

22. Hawley CJ, Gale TM, Sivakumaran T: Defining remission by cut off score on the MADRS: selecting the optimal value. J Affect Disord 2002; 72:177-184

23. Cohen Cl, Amassian VE, Akande B, Maccabee PJ: The efficacy and safety of bilateral rTMS in medication-resistant depression. J Clin Psychiatry 2003; 64:613-614

24. Hausmann A, Kemmler G, Walpoth M, Mechtcheriakov S, Kramer-Reinstadler K, Lechner T, Walch T, Deisenhammer EA, Kofler M, Rupp Cl, Hinterhuber H, Conca A: No benefit derived from repetitive transcranial magnetic stimulation in depression: a prospective, single centre, randomised, double blind, sham controlled "add on" trial. J Neurol Neurosurg Psychiatry 2004; 75:320-322

25. Conca A, Di Pauli J, Beraus W, Hausmann A, Peschina W, Schneider $\mathrm{H}$, Konig $\mathrm{P}$, Hinterhuber $\mathrm{H}$ : Combining high and low frequencies in rTMS antidepressive treatment: preliminary results. Hum Psychopharmacol 2002; 17:353-356

26. Nahas Z, Lomarev M, Roberts DR, Shastri A, Lorberbaum JP, Teneback C, McConnell K, Vincent DJ, Li X, George MS, Bohning DE: Unilateral left prefrontal transcranial magnetic stimulation (TMS) produces intensity-dependent bilateral effects as measured by interleaved BOLD fMRI. Biol Psychiatry 2001; 50:712720 